\title{
Evaluation of a comprehensive diabetes disease management program: Progress in the struggle for sustained behavior change
}

\author{
Janice Clarke \\ Thomas Jefferson University \\ Albert Crawford \\ Thomas Jefferson University \\ David B. Nash \\ Thomas Jefferson University
}

Follow this and additional works at: https://jdc.jefferson.edu/healthpolicyfaculty

Part of the Health Services Research Commons

Let us know how access to this document benefits you

\section{Recommended Citation \\ Clarke, Janice; Crawford, Albert; and Nash, David B., "Evaluation of a comprehensive diabetes disease management program: Progress in the struggle for sustained behavior change" (2002). College of Population Health Faculty Papers. Paper 6. \\ https://jdc.jefferson.edu/healthpolicyfaculty/6}

This Article is brought to you for free and open access by the Jefferson Digital Commons. The Jefferson Digital Commons is a service of Thomas Jefferson University's Center for Teaching and Learning (CTL). The Commons is a showcase for Jefferson books and journals, peer-reviewed scholarly publications, unique historical collections from the University archives, and teaching tools. The Jefferson Digital Commons allows researchers and interested readers anywhere in the world to learn about and keep up to date with Jefferson scholarship. This article has been accepted for inclusion in College of Population Health Faculty Papers by an authorized administrator of the Jefferson Digital Commons. For more information, please contact: JeffersonDigitalCommons@jefferson.edu. 


\title{
Evaluation of a Comprehensive Diabetes Disease Management Program: Progress in the Struggle for Sustained Behavior Change
}

\author{
JANICE CLARKE, R.N., B.B.A., ALBERT CRAWFORD, Ph.D., \\ and DAVID B. NASH, M.D., M.B.A.
}

\begin{abstract}
The successful management of diabetes with a goal of achieving near-normoglycemia requires patients to make multiple lifestyle changes as part of an intensive, complex, and coordinated therapeutic regimen aimed at reducing the risk of complications associated with the disease. The difficulty in creating and sustaining these lifestyle behavior changes is a major stumbling block in achieving the desired therapeutic goal. An underlying assumption of comprehensive disease management is that regular, personal contact with nurses and ancillary health professionals will facilitate these lifestyle behavior changes for program participants. The results of a survey of self-reported data from 750 participants in a comprehensive diabetes management program, reported on here, show strong perceptions of positive behavior change over the broad range of medical and lifestyle treatment areas associated with effective management of diabetes. These results suggest that diabetes disease management programs are an effective approach to helping diabetic patients accomplish the lifestyle behaviors critical to their health.
\end{abstract}

\section{INTRODUCTION}

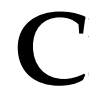
HRONIC DISEASES such as diabetes, asthma, coronary artery disease, and hypertension have replaced acute and infectious diseases as the major cause of death and disability in the United States. According to statistics reported by the Institute on Health and Aging, chronic diseases affect over 100 million Americans and account for $75 \%$ of national health care costs. Among chronic diseases, diabetes may be the "poster child," with its broad-ranging complexity and costliness, in both human and financial terms. Increasingly common and dis- turbingly under-diagnosed, diabetes affects nearly 16 million U.S. individuals and contributes to almost 200,000 deaths per year. ${ }^{1}$ Total direct and indirect costs attributed to diabetes in the United States approach $\$ 105$ billion per year. $^{2}$ As the population continues to age, so the prevalence and the costs of diabetes are expected to rise. Recent studies project a rise of at least $15 \%$ by the year 2010 and $60 \%$ by $2050 .^{3}$

For people with diabetes, adhering to recommended treatment regimens has never been simple; but in recent years it has become a formidable challenge. Based on compelling evidence from two landmark studies, the Diabetes 
Control and Complications Trial (DCCT) and the United Kingdom Prospective Diabetes Study (UKPDS), ${ }^{4,5}$ the current treatment goal for people with diabetes has escalated from mere blood glucose control to near-normoglycemia. The DCCT and UKPDS studies demonstrated the importance of optimal glucose control in reducing the risk, or delaying the progression, of serious complications of the disease for both type 1 (insulin dependent) and type 2 patients. With near normoglycemia as the new "gold standard," the ongoing care and treatment strategies recommended by the American Diabetes Association (ADA) have intensified. ${ }^{6}$ More frequent monitoring and sustained adherence to medication, diet, and exercise regimens are typically required to achieve the desired level of glycemic control. It follows that providing optimal treatment makes greater demands of the primary care provider-and achieving the best outcomes places increased burdens on the diabetic patient, physician, and health care system alike.

Diabetes is one of the most psychologically and behaviorally demanding of the chronic medical illnesses. ${ }^{7}$ The outcome of diabetes treatment is highly dependent on the self-care behavior of the patient. It is estimated that patients are expected to conduct $95 \%$ of their own diabetes management. ${ }^{8}$ Patients with diabetes are expected to make multiple lifestyle changes simultaneously. The complexity involved in achieving optimal control requires almost "fanatic-like" behavior from the patient with diabetes as he or she strives to understand the effect of exercise, medications, dietary intake, and stress on blood glucose levels. Moreover, the self-management process is not static-patients must learn to understand the complex physiological changes in their bodies and to incorporate these changes into their self-management decisions. ${ }^{9}$

Failure to sustain desired behaviors is associated with a high risk of complications, but patients with diabetes often do not fully understand their illness, take their medication correctly, or make lifestyle changes recommended by their physicians. Further, they often lack the emotional support necessary for coping with their condition. ${ }^{10}$

Collaborative relationships between health care providers and their patients with diabetes may be the most important element in improving patient adherence and outcomes. ${ }^{8}$ However, for time-pressed primary care providers who manage the clinical care of most of these patients, the demands for medical care, monitoring, social and emotional support, education and reeducation required by this complex, progressive disease are often overwhelming. Statistics reported by the U.S. Department of Health and Human Services (DHHS) in 2000 suggest that medical care for diabetes as currently practiced in the United States neither meets the ADA guidelines nor approaches the levels of the treatment groups documented in the DCCT or UKPDS. ${ }^{15}$ While a variety of reasons are generally offered for this, perhaps the most valid explanation is the lack of an integrated, coordinated care management system designed to support both the patient and the physician in creating and sustaining the desired self-management behaviors across the entire health care delivery spectrum.

\section{Contributions of behavioral science and diabetes education}

Nonadherence to medication regimens is a major problem in all therapeutic areas, ranging from $30 \%$ to $60 \%$, with the higher rates occurring in symptom-free patients. ${ }^{11}$ As noted by Glasgow et al. in their review of behavioral science contributions, ${ }^{12}$ other studies have found that, while adherence to medication regimens is a problem, compliance is poorest in the areas involving other lifestyle modifications such as dietary change and home glucose monitoring.

Behavioral science has developed theories and provided frameworks for understanding and studying nonadherence and its determinants. The Health Belief Model (HBM), for instance, recognizes and explains the relationship between perceived health benefits and a patient's success with self-care. The Transtheoretical Model described by Prochaska et al. defines behavior change as occurring in five distinct stages: precontemplation, contemplation, preparation, action, and maintenance. ${ }^{13}$ While a theoretical model, it is particularly useful in diabetes education in that it recognizes 
behavior change as a continuum and identifies success in terms of progress toward change as well as in terms of a realized outcome of the change.

The field of diabetes education has also produced insights into diabetes patient behavior change and "self-efficacy." The concept of "patient empowerment" has been applied to diabetes education to ensure that the choices made by patients living with diabetes are informed choices. Studies suggest that patient empowerment is an effective approach to developing educational interventions for addressing the psychosocial aspects of the disease and, by implication, that it is conducive to improving blood glucose control. ${ }^{14}$

The translation of these behavioral concepts into practice requires systems and resources designed to support both patients and physicians in actualizing the behavior changes identified as critical success factors for effective selfmanagement.

\section{Disease management as an approach for creating} and sustaining positive behavior change

Patient success in adhering to healthcare regimens requiring changes in behavior and lifestyle is associated with rapport with health care professionals who play a role in engendering optimism, maintaining enthusiasm, and facilitating and encouraging maintenance of health behaviors. ${ }^{10}$ Traditional strategies have focused on diabetes education classes with certified diabetes educators and nutritionists, and diabetes education assistance in physicians' offices, often provided as outreach by teaching hospitals. The ADA has advocated a physiciancoordinated team approach to diabetes care management. These teams might include nurses, nutritionists and behavioral health professionals with expertise in diabetes care and treatment. There is considerable evidence that these traditional educational approaches have positive effects on outcomes. However, these approaches would be difficult to apply to large numbers of patients with diabetes simultaneously. They do not offer promise as a resolution to the national delivery system problems underlying the DHHS findings cited above.

Over the past decade, disease management programs have emerged as a framework for supporting interventions to effect positive behavior changes in patients with chronic illnesses, particularly diabetes. Disease management is generally defined as "a system of coordinated healthcare interventions and communications for populations with conditions in which patient self-care efforts are significant" (DMAA Definition of Disease Management). Focusing on both clinical and non-clinical interventions, disease management programs address a disease or condition in a manner that maximizes effectiveness and efficiency regardless of treatment settings or customary reimbursement methods. The overriding goal is to prevent acute exacerbation of the disease and the accompanying use of expensive resources by emphasizing prevention, proactive care management and effective integration and coordination of care processes across the provider spectrum. ${ }^{16}$ Through this approach, disease management programs help patients and their physicians to better adhere to the recognized standards of care and prevent avoidable utilization of health care resources.

Proponents of disease management believe that, when effectively designed and implemented, it offers substantial promise to improve health outcomes, thereby reducing overall costs. The disease management model shifts the focus from "utilization management" (i.e., targeting the sickest and/or highest risk patients) to a population-based approach involving identification and stratification of all patients diagnosed with a particular disease. In combination with the structures of modern health plans, the disease management model presents a powerful opportunity for improving upon the traditional model for managing diabetes. Existing health plan structures incorporate the requisite range of healthcare providers and services, provide operational and informational tools to support positive change, and are the repository for the data necessary to manage change.

On a national level, the Institute of Medicine (IOM) has recognized the enormous potential of the disease management model. In "Crossing the Quality Chasm: A New Health System for the 21st Century," the IOM calls for the expansion of disease management services for 
chronic illnesses as an integral part of a smoothly functioning healthcare system.

\section{American Healthways (AMHC): description of the Diabetes Healthways ${ }^{S M}$ program}

American Healthways, a recognized leader in the field of disease management and the largest publicly traded disease management organization in the nation, has successfully partnered with health plans to enhance the care of their members with chronic diseases. AMHC's disease-specific "Healthways" programs offer a broad scope of services and components from which a health plan may tailor a program to its unique member population and provider network. A distinctive feature of the Diabetes Healthways $^{\mathrm{SM}}$ program is that once a patient is identified and participating, the program coordinates all of the patient's health care needs. In providing support to patients, whether or not their needs are related to diabetes, the program effectively treats the person rather than the disease.

In 2000, AMHC contracted to provide a comprehensive diabetes disease management program for a health plan serving approximately 800,000 members over a statewide area in the midwestern United States. Under the terms of this agreement, AMHC provided its Diabetes Healthways ${ }^{\mathrm{SM}}$ program to the plan's "risk" and "Medicare + Choice" members diagnosed with diabetes who did not opt-out of participation. (Note: The "opt-out" rate for this plan was $3 \%$.)

AMHC's programs are provided on an "engagement" basis to all of the health plan's subscribers identified as having diabetes through retrospective review of pharmaceutical and other medical claims; that is, all identified diabetics are automatically enrolled rather than invited to enroll. Once identified and enrolled, diabetic members are classified according to AMHC's proprietary, four-tiered population stratification model to assure that members receive the appropriate frequency and intensity of interventions. The strata range from the healthiest group (stratum 1), currently showing no indicators for meaningful risk of health compromise, to the highest risk group (stratum 4 ), with severe health and/or behavior prob- lems adversely affecting their health status. The initial stratification incorporates behavioral data provided by the member and the primary physician in addition to health status information and utilization patterns provided by the health plan. The stratification model is dynamic, allowing for changes based on new data and the member's changing health status.

The AMHC Diabetes Healthways ${ }^{\mathrm{SM}}$ program is based on American Diabetes Association Guidelines and features ADA Standards of Care in its core content. The program protocol for all participants, regardless of stratification level, includes mailed letters of introduction and welcome kits; scheduled outbound "Care Calls" as well as a "hot line" for inbound member calls; and periodic "reminder card" and newsletter mailings. The program provides parallel communications-for example, introductory letter and welcome kit, Standard of Care notices-with the members' primary care physicians. An electronic database equipped with proprietary software enables AMHC personnel to track program participants' medical claims, drug prescriptions, nature and frequency of laboratory tests and, in most cases, laboratory test results.

The core of the program is the "Care Call," an outbound personal communication between a specially trained nurse and the patient. Care Calls are regularly scheduled telephonic interactions between AMHC's nurses and program participants. Each call may include, but is not limited to: diabetes education, including identification of knowledge deficits; establishment of and progress in meeting self-care goals; review of adherence to medication regimen and the primary physician's treatment plan; review of specific problems and interventions initiated to address those issues; identification of new problems the member is experiencing; and reminders about standards of care. Typically, Care Calls reinforce positive behaviors such as taking medications as prescribed, adhering to appointment schedules, and doing or getting appropriate medical tests. AMHC's nurses also discuss diabetes-specific preventive measures, stress factors and, if relevant, smoking cessation and alcoholic beverage consumption. On an annual basis, the nurses administer a General Health Assessment, a Depression Risk As- 
sessment Screening, and a Quality of Life Survey for each program participant. The frequency of scheduled Care Calls ranges from quarterly to daily according to stratification level and individual patient needs.

For participants in all but the lowest risk stratum (asymptomatic), the program features the formation of a documented self-care goal agreement focused on defining a plan for positive behavior change. This is accomplished telephonically, and is supplemented by a series of scheduled Care Calls providing individualized education, advocacy and physician treatment plan support. On an acute basis, calls focus on problem-specific assessments and problem-specific interventions. The intensity and frequency of calls follows the proprietary stratification protocol. Communication of critical information or "alert values" to physicians is made as appropriate.

Central to the effectiveness of the Care Call is the development and maintenance of trusting relationships between $\mathrm{AMHC}^{\prime}$ s nurses and the program participants. It is hypothesized that these regularly occurring, personal contacts with the nurses (and other ancillary health professionals who make up the patient's AMHC care team) help patients to manage their diets, achieve blood glucose and cholesterol targets, and in general facilitate the behaviors necessary for reducing the incidence of, or retarding the development of, complications.

An overriding goal of AMHC's Diabetes Healthways ${ }^{\mathrm{SM}}$ program is to reinforce the positive behaviors, attitudes, skills, and knowledge of its participants. Patient adherence to medical treatment regimens, and the requisite lifestyle modifications, is expected to bring about the desired clinical outcomes, and, as a result, the desired financial outcomes. Aggregate clinical process and cost data indicate that the program is achieving these objectives.

\section{MATERIALS AND METHODS}

Evaluation of the overall impact of the Diabetes Healthways ${ }^{\mathrm{SM}}$ program typically includes clinical quality process and objective outcome measures, member and physician satisfaction measures and financial measures. Because patient behavior change is so critical to the success of a diabetes management program, AMHC undertook a study to assess the presence and extent of positive behavior changes in enrolled diabetes patients as part of its overall process for regular and comprehensive program quality evaluations.

\section{Study design, population, and sampling rationale}

As illustrated in Table 1, a five-group, proportionally allocated, random sampling design was employed to quantify the extent to which program participants perceived that their behaviors changed since enrolling in the program.

The sample was drawn from the entire eligible population in order to obtain a statistically valid set of responses representative of that population. To be included in the study, diabetes members (i.e., members with diabetes as their primary medical condition, without any evidence of congestive heart failure) must have been documented as continuously enrolled between the initial date of member eligibility and the study population creation date $(10 / 31 / 2001)$, and must have received a minimum of one Care Call. To ensure appropriate representation of all inter-

Table 1. Proportional Allocation of Study Population

\begin{tabular}{llcc}
\hline Group & No. of care calls & Population & No. of completed surveys \\
\hline 1 & 1-2 Care Calls & 431 & 149 \\
2 & 2-3 Care Calls & 430 & 150 \\
3 & 3-6 Care Calls & 430 & 149 \\
4 & 6-8 Care Calls & 430 & 149 \\
5 & Over 8 Care Calls & 430 & 151 \\
Total & & 2,151 & 748 \\
\hline
\end{tabular}


vention levels in the study, members meeting study inclusion criteria were arrayed from least to most Care Calls, providing the basis for the five groupings. From this ordering, members were divided into five proportionally allocated groups. Further, members within each group were randomized to ensure that the final sample would accurately represent the population from which it was drawn.

\section{Survey instrument and method of administration}

The survey instrument, a 10-item questionnaire with a four-point rating scale (plus a "not applicable/don't know" rating), was developed by AMHC's Informatics Department. The questions were designed to elicit participant perceptions regarding changes in their behavior in the key areas addressed, that is, eating habits, taking medications and recommended tests, attending to test results, stopping/reducing smoking and drinking, increasing physical activity, increasing use of preventive health services, and reducing stress. The survey was administered telephonically by an unaffiliated, independent market research organization that provided training on appropriate interview techniques to its staff. Survey calls were monitored and completed surveys were reviewed at random by supervisory staff. In order to assure equal representation across the five groups, approximately 150 surveys were completed per group (Table 1).

\section{Survey inclusion criteria}

To be eligible for inclusion in the study, members were required to meet the following minimum qualifications: documented as being continuously enrolled in the disease management program from the program's inception date or from the date of eligibility; 18 years of age or older as of $10 / 31 / 2001$; having a valid telephone number; and having a minimum of one successfully completed Care Call.

\section{RESULTS}

A total of 1,720 telephone calls were attempted in order to complete a total of 748 surveys (a $43 \%$ success rate). There were no sig- nificant age or gender effects - the average age of respondents was 59 years and $386(51 \%)$ respondents were female. Forty-one percent (305) of respondents received a "high number" (six or more) of Care Calls, and 59\% (447) received a "low number" of Care Calls (less than six). The average number of Care Calls received per respondent was 5.18. When viewed by risk stratification level, the respondent group closely reflected the distribution of the total program population: $24(3 \%)$ in stratum $1 ; 299$ $(40 \%)$ in stratum $2 ; 354(47 \%)$ in stratum 3 ; and $75(10 \%)$ in stratum 4 . Likewise, the age distribution for survey respondents was similar to that of the population: $87(11 \%)$ at $18-44$ years of age; $396(54 \%)$ at $45-64$ years of age; and, 262 $(35 \%)$ greater than 64 years of age.

Table 2 contains the frequency distribution of responses by question. As illustrated, the total perceived behavior change (i.e., all responses of "somewhat," "moderately," and "a lot") ranged from a low of $65.2 \%$ on question 5 ("stopped or reduced smoking") to a high of 93.9\% on question 7 ("improved on taking recommended medical tests"). Total responses to question 5 ("stopped or reduced smoking") and question 6 ("stopped or reduced drinking") suggest that relatively few of these program participants were preintervention smokers and/or drinkers. "Not applicable" was the answer given by $62 \%$ (544) of the respondents for question 5 and by 74\% (594) of the respondents for question 6. Disregarding questions 5 and 6 , over $87 \%$ of the total responses for the other eight questions support the assertion that participation in the AMHC Diabetes Healthways $^{\mathrm{SM}}$ program effects favorable behavioral change.

A general linear model (GLM) was developed to examine the effects of risk stratification levels and Care Calls on perceived behavior change indicators. Table 3 shows mean scores for each survey question (excluding question 5 and question 6) by Care Call frequency group, including statistical controls for the effects of Risk Stratification Level. For example, respondents receiving one to five Care Calls had a mean perceived improvement in eating habits of 3.26 (where the number " 3 " represents the response "moderately" and the number " 4 " represents the response "a lot"), while those respondents receiving six 
Table 2. Frequency Distributions: Behavior Change Indicators

\begin{tabular}{|c|c|c|c|c|c|}
\hline $\begin{array}{l}\text { Indicator/ } \\
\text { survey } \\
\text { question }\end{array}$ & Not at all & Somewhat & Moderately & A lot & $\begin{array}{l}\text { Total } \\
\text { behavior } \\
\text { change }^{\mathrm{a}}\end{array}$ \\
\hline $\begin{array}{l}\text { 1. Improved eating } \\
\text { habits }\end{array}$ & $\begin{array}{c}95 \\
13.63 \%\end{array}$ & $\begin{array}{c}352 \\
50.50 \%\end{array}$ & $\begin{array}{c}160 \\
22.96 \%\end{array}$ & $\begin{array}{c}90 \\
12.91 \%\end{array}$ & $\begin{array}{c}602 \\
86.37 \%\end{array}$ \\
\hline $\begin{array}{l}\text { 2. Improved taking } \\
\text { medications }\end{array}$ & $\begin{array}{c}105 \\
14.8 \%\end{array}$ & $\begin{array}{c}256 \\
36.16 \%\end{array}$ & $\begin{array}{c}175 \\
24.72 \%\end{array}$ & $\begin{array}{c}172 \\
24.29 \%\end{array}$ & $\begin{array}{c}603 \\
85.17 \%\end{array}$ \\
\hline $\begin{array}{l}\text { 3. Increased physical } \\
\text { activity }\end{array}$ & $\begin{array}{c}111 \\
15.42 \%\end{array}$ & $\begin{array}{c}324 \\
45.00 \%\end{array}$ & $\begin{array}{c}196 \\
27.22 \%\end{array}$ & $\begin{array}{c}89 \\
12.36 \%\end{array}$ & $\begin{array}{c}609 \\
84.58 \%\end{array}$ \\
\hline $\begin{array}{l}\text { 4. Increased discussion } \\
\text { about medical } \\
\text { condition }\end{array}$ & $\begin{array}{c}86 \\
11.65 \%\end{array}$ & $\begin{array}{c}271 \\
36.72 \%\end{array}$ & $\begin{array}{l}237 \\
32.11 \%\end{array}$ & $\begin{array}{c}144 \\
19.51 \%\end{array}$ & $\begin{array}{c}652 \\
88.34 \%\end{array}$ \\
\hline $\begin{array}{l}\text { 5. Stopped or reduced } \\
\text { smoking }\end{array}$ & $\begin{array}{c}72 \\
34.78 \%\end{array}$ & $\begin{array}{c}58 \\
28.02 \%\end{array}$ & $\begin{array}{c}47 \\
22.71 \%\end{array}$ & $\begin{array}{c}30 \\
14.49 \%\end{array}$ & $\begin{array}{c}135 \\
65.22 \%\end{array}$ \\
\hline $\begin{array}{l}\text { 6. Stopped or reduced } \\
\text { drinking }\end{array}$ & $\begin{array}{c}40 \\
25.64 \%\end{array}$ & $\begin{array}{c}56 \\
35.90 \%\end{array}$ & $\begin{array}{c}39 \\
25.00 \%\end{array}$ & $\begin{array}{c}21 \\
13.46 \%\end{array}$ & $\begin{array}{c}116 \\
74.36 \%\end{array}$ \\
\hline $\begin{array}{l}\text { 7. Improved on taking } \\
\text { recommended medical } \\
\text { tests }\end{array}$ & $\begin{array}{c}45 \\
6.14 \%\end{array}$ & $\begin{array}{c}250 \\
34.11 \%\end{array}$ & $\begin{array}{c}279 \\
38.06 \%\end{array}$ & $\begin{array}{c}159 \\
21.69 \%\end{array}$ & $\begin{array}{c}688 \\
93.86 \%\end{array}$ \\
\hline $\begin{array}{l}\text { 8. Paid closer attention } \\
\text { to medical results }\end{array}$ & $\begin{array}{c}46 \\
6.22 \%\end{array}$ & $\begin{array}{c}220 \\
29.73 \%\end{array}$ & $\begin{array}{c}232 \\
31.35 \%\end{array}$ & $\begin{array}{c}242 \\
32.70 \%\end{array}$ & $\begin{array}{c}694 \\
93.78 \%\end{array}$ \\
\hline $\begin{array}{l}\text { 9. Increased use of } \\
\text { preventive health } \\
\text { services }\end{array}$ & $\begin{array}{c}80 \\
10.85 \%\end{array}$ & $\begin{array}{c}260 \\
35.28 \%\end{array}$ & $\begin{array}{c}242 \\
32.84 \%\end{array}$ & $\begin{array}{c}155 \\
21.03 \%\end{array}$ & $\begin{array}{c}657 \\
89.15 \%\end{array}$ \\
\hline $\begin{array}{l}\text { 10. Spent less time } \\
\text { worrying about } \\
\text { condition }\end{array}$ & $\begin{array}{c}131 \\
18.40 \%\end{array}$ & $\begin{array}{c}273 \\
38.34 \%\end{array}$ & $\begin{array}{c}197 \\
27.67 \%\end{array}$ & $\begin{array}{c}111 \\
15.59 \%\end{array}$ & $\begin{array}{c}581 \\
81.60 \%\end{array}$ \\
\hline
\end{tabular}

aTotal behavior change is the sum of the values of "somewhat," "moderately," and "a lot."

or more Care Calls had a mean perceived improvement of 3.47 .

Where significant, the effects of Care Calls on behavior change indicators when control- ling for risk stratum are shown. Both the risk stratum and the number of Care Calls appear to have an effect on perceived behavior change.

Table 3. General Linear Model ${ }^{a}$ Results: Perceived Behavior Change Mean Score by Number of Care Calls, Controlling for Age Group, Gender, and Risk Stratum

\begin{tabular}{|c|c|c|c|}
\hline Indicator/survey question ${ }^{\mathrm{b}}$ & $\begin{array}{l}\text { BCI: } 1-5 \\
\text { care calls }\end{array}$ & $\begin{array}{l}\text { BCI: } 6+ \\
\text { care calls }\end{array}$ & $\mathrm{F}, \mathrm{p}$ \\
\hline 1. Improved eating habits & 3.26 & 3.47 & $\begin{array}{l}F=5.85 \\
p<0.05\end{array}$ \\
\hline 2. Improved taking medications & 3.58 & 3.59 & $p=$ n.s. \\
\hline 3. Increased physical activity & 3.36 & 3.37 & $p=$ n.s. \\
\hline $\begin{array}{l}\text { 4. Increased discussion about medical } \\
\text { condition }\end{array}$ & 3.50 & 3.73 & $\begin{array}{l}F=8.11 \\
p<0.01\end{array}$ \\
\hline $\begin{array}{l}\text { 7. Improved on taking recommended } \\
\text { medical tests }\end{array}$ & 3.68 & 3.86 & $\begin{array}{l}F=5.58 \\
p<0.05\end{array}$ \\
\hline 8. Paid closer attention to medical results & 3.81 & 4.04 & $\begin{array}{l}F=8.93 \\
p<0.01\end{array}$ \\
\hline $\begin{array}{l}\text { 9. Increased use of preventive health } \\
\text { services }\end{array}$ & 3.60 & 3.70 & $p=$ n.s. \\
\hline $\begin{array}{l}\text { 10. Spent less time worrying about } \\
\text { condition }\end{array}$ & 3.35 & 4.49 & $p=$ n.s. \\
\hline
\end{tabular}

aSAS PROC GLM for unbalanced analysis of variance (ANOVA) designs.

${ }^{\mathrm{b}}$ Questions 5 and 6 (reducing smoking and drinking) were excluded from these analyses. 
The survey findings are even more persuasive when viewed in combination with clinical process outcomes for the program. More than $93 \%$ of survey respondents reported improvement in taking recommended medical tests. As shown in Table 4, there were dramatic, program-wide increases in testing for $\mathrm{HbA1c}$, LDL cholesterol, diabetic retinopathy and microalbuminuria for the enrolled diabetic population during the first year of the Diabetes Healthways $^{\mathrm{SM}}$ program.

Of further interest are the results of a cost analysis for the program. In the relatively short-term (the first year of the program), costs for program participants (i.e., total population of members with diabetes, with or without CHF) decreased from an adjusted baseline of \$559.44 PM/PM (1999) to \$503.07 PM/PM for the study period, a $10.1 \%$ reduction. For the same period, costs for the nondiabetes members in this health plan increased by $21.2 \%$.

\section{DISCUSSION}

The Care Call component of the Diabetes Healthways ${ }^{\mathrm{SM}}$ program focuses on improving participants' understanding of their disease and the crucial importance of adhering to the recognized standards of care while providing support in helping them to change their behaviors and lifestyles to accommodate the intensive treatment regimens. The findings of this survey of perceived behavior change in program participants are uniformly positive, strongly so in a majority of the areas emphasized by the Diabetes Healthways ${ }^{\mathrm{SM}}$ program.
It is recognized that self-reported measures must be viewed with some caution. For example, a recent study examining the relationship between actual $\mathrm{Hb} \mathrm{A} 1 \mathrm{c}$ test rates and various self-reported measures of health status found substantial differences between the patients' perceptions of health status and satisfaction with care and the actual medical care they received. ${ }^{17}$ Nevertheless, the findings of this survey show a strong correlation between perceived behavior change and actual outcomes, suggesting a high probability of causality.

It is impossible to establish absolute causality when dealing with a complex, multifaceted program for a disease such as diabetes. In addition to internal programmatic factors, external factors ranging from the increase in public awareness of diabetes to the involvement of the National Committee on Quality Assurance (NCQA) in monitoring diabetes treatment (HEDIS standards reporting requirements) introduce variables of indeterminate impact on the behavior of participants in disease management programs.

An obvious weakness in the study is the lack of a clinical outcomes measure, i.e. a change in the $\mathrm{HbA} 1 \mathrm{c}$ test results for the study population. However, behavioral scientists such as Sanazaro and Williamson make a strong case that, while not a direct measure of improvement or deterioration in health status, compliance may be influenced by and/or result from a health care intervention, leading to improved outcomes. ${ }^{18}$ They make a convincing case for "compliance" as a valuable process outcome. Some have defined compliance as an "intermediate outcome" which is useful in evaluat-

\begin{tabular}{|c|c|c|c|}
\hline \multirow[b]{2}{*}{ Process measure } & \multirow{2}{*}{$\frac{\text { Baseline (1999), } \mathrm{n}=2,982}{\text { Number }(\%)}$} & \multicolumn{2}{|c|}{ First year $(6 / 00-5 / 01), \mathrm{n}=3,144$} \\
\hline & & Number (\%) & Chi-square value \\
\hline At least $1 \mathrm{HbA} 1 \mathrm{c}$ & $1,581(53.0)$ & 2,441 (77.6) & $2,175(p<0.001)^{a}$ \\
\hline At least $2 \mathrm{HbA} 1 \mathrm{c}$ & 755 (25.3) & $1,547(49.2)$ & $1,065(p<0.001)^{a}$ \\
\hline LDL & 1,056 (35.4) & $1,980(63.0)$ & $1,600(p<0.001)^{\mathrm{a}}$ \\
\hline DRE & 523 (17.5) & 735 (23.4) & $201(p<0.001)^{a}$ \\
\hline Microalb. & 399 (23.4) & 993 (31.6) & $570(p<0.001)^{a}$ \\
\hline
\end{tabular}


ing the means by which a disease management program can improve outcomes. Self-reported or objective measures of adherence/compliance are included in this definition.

Specific characteristics of a population dramatically affect behaviors, perceptions and outcomes. The subjects in this study were members of a commercial health plan in the southwestern United States. A multicultural, northeastern, urban population may have very different motivators and responses than the population represented in the study. Given previous geographically dispersed outcomes reported for other health plans using AMHC's Diabetes Healthways ${ }^{\mathrm{SM}}$ programs, we suspect that the results found in the population studied are likely to be similar in other populations.

\section{CONCLUSION}

Comprehensive patient-centered diabetes management programs, focused on providing proactive, personal support for patients with diabetes, hold promise for ending the struggle to create and sustain patient behavior change. Results of a survey of 750 participants in a Diabetes Healthways ${ }^{\mathrm{SM}}$ diabetes disease management program show strong evidence of perceived positive behavior change in ten critical treatment areas. When viewed in combination with positive clinical process outcomes and reduced PMPM costs for the entire program, these findings are even more compelling. While the survey does not prove any causal linkages as a result of the Diabetes Healthways ${ }^{\mathrm{SM}}$ program, it does demonstrate that the perceived changes were not the result of random chance. Absent any other significant factors, it is reasonable to conclude that the program was a primary contributor to both the perceived and reported results.

Increasingly, behavioral scientists are recognizing diabetes treatment as predominantly behavioral, that is, promoting self-management. ${ }^{12}$ There is ample evidence in the health behavior literature of a growing acceptance of behavior change as an outcome-or "intermediate outcome" - on its own merits. In evaluating the performance of a multifaceted disease management program such as Diabetes Health- ways $^{\mathrm{SM}}$, a measure of behavior change is valuable, particularly when viewed in combination with improvement in patients' health status and satisfaction as well as in terms of cost savings.

In "Crossing the Quality Chasm," the Institute of Medicine (IOM) recognized the pivotal role of ongoing management of chronic illness in a smoothly functioning healthcare system and called for expansion of disease management services. ${ }^{19}$ The IOM has also called for additional research into appropriate outcome measures for gauging the success of disease management programs. Progress is being made in developing universally accepted definitions of the attributes of disease management programs such as optimal program delivery (e.g., means of identification, engagement versus enrollment, telephone versus on-line), components, and outcomes reporting. The Disease Management Association of America (DMAA) has published an industry standard definition and is embarking on an effort to develop an industry standard outcomes reporting methodology. Other organizations such as the National Committee on Quality Assurance (NCQA) and the Disease Management Advisory Council (DMAC) are making headway on accreditation and evaluation programs for disease management.

Validated and peer-reviewed large-scale outcomes studies from comprehensive diabetes disease management programs are beginning to appear regularly in the literature. The sum impact of these studies is strongly positive in demonstrating the effectiveness of these programs in helping participants to make and sustain the behavior changes necessary for improving their health status while reducing costs.

\section{ACKNOWLEDGMENTS}

This study was supported by an unrestricted grant from American Healthways. The cooperation of American Healthways staff (Thad Perry, Ph.D., Senior Director of Informatics, Travis L. Tucker, M.A., Business Analyst, and Brent Hamar, D.D.S., M.P.H., Manager of Informatics) and the staff of Thomas Jefferson 
University's Office of Health Policy and Outcomes Research (Renee Liberoni, M.P.H., Project Manager) is greatly appreciated.

\section{REFERENCES}

1. Centers for Disease Control and Prevention, National Center for Chronic Disease Prevention and Health Promotion. Diabetes: A growing public health problem. Available at www.cdc.gov/diabetes/pubs. Accessed June 25, 2001.

2. Rubin RJ, Altman WM, Mendelson DN. Health care expenditures for people with diabetes mellitus, 1992. J Clin Endocrinol Metab 1994;78:809A-809F.

3. Institute for Health and Aging, University of California, San Francisco, for the Robert Wood Johnson Foundation. Chronic care in America: A 21st century challenge. Princeton, NJ: IHA, 1996.

4. Diabetes Control and Complications Trial Research Group. The effect of intensive treatment of diabetes on the development and progression of long-term complications in insulin-dependent diabetes mellitus. N Engl J Med 1993;329:977-986.

5. UK Prospective Diabetes Study (UKPDS) Group. Intensive blood-glucose control with sulfonylureas or insulin compared with conventional treatment and risk of complications in patients with type 2 diabetes. Lancet 1998;352:837-853.

6. American Diabetes Association. Standards of medical care for patients with diabetes mellitus. Diabetes Care 2001; 24. Available at www.diabetes.org/clinicalrecommendations. Accessed June 20, 2001.

7. Cox DJ, Gonder-Frederick L. Major developments in behavioural diabetes research. J Consult Clin Psychol 1992;60:628-638.

8. Ciechanowski PS, Katon WJ, Russo JE, Walker EA. The patient-provider relationship: attachment theory and adherence to treatment in diabetes. Am J Psychiatry 2001;158:29-35.

9. Sullivan ED, Joseph DH. Struggling with behavior changes: a special case for clients with diabetes. Diabetes Educator 1998;24:72-76.

10. Lo R. Correlates of expected success at adherence to health regimen of people with IDDM. J Adv Nurs 1999;30:418-424.
11. Daily G, Kim MS, Lian JF. Patient compliance and persistence with anti-hyperglycemic drug regimens: evaluation of a Medicaid patient population with type 2 diabetes mellitus. Clin Ther 2001;23:1311-1320.

12. Glasgow RE, Fisher EB, Anderson BJ, Behavioral science in diabetes: contributions and opportunities. $\underline{\mathrm{Di}}-$ abetes Care 1999;22:832-842.

13. Rimer BK. Perspectives on interpersonal theories in health education and health behavior. In: Glanz $\mathrm{K}$, Lewis FM, Rimer BK, eds. Health behavior and health education: theory, research and practice. Jossey-Bass, New York, New York: 1990:140-160.

14. Anderson RM, Funnell MM, Butler PM, Arnold MS, Fitzgerald JT, and Feste CC. Patient empowerment: results of a randomized controlled trial. Diabetes Care 1995;18:943-949.

15. Harris MI, Eastman RC, Siebert C. The DCCT and medical care for diabetes in the U.S. Diabetes Care 1994;17:761-64.

16. Zitter M. A new paradigm in health care delivery: disease management. In: Todd WE, Nash D, eds. Disease management: a systems approach to improving patient outcomes. American Hospital Publishing, Chicago, Illinois: 1997:1-25.

17. Wasserman J, Boyce-Smith G, Hopkins DSP, et al. A comparison of diabetes patients' self-reported health status with hemoglobin A1c test results in 11 California health plans. Managed Care 2001; March:58-70.

18. Doyle JB. Health outcomes: measuring and maximizing value in disease management. In: Todd WE, Nash D, eds. Disease management: a systems approach to improving patient outcomes. American Hospital Publishing, Chicago, Illinois: 1997:61-85.

19. Nash DB. The DMAC of NCQA [editorial]. Health Policy Newsletter 2001;14:1-2.

Address reprint requests to: Janice Clarke, R.N., B.B.A. Office of Health Policy and Clinical Outcomes Thomas Jefferson University Hospital 1015 Walnut Street, Suite 115 Philadelphia, PA 19107

E-mail: janice.clarke@mail.tju.edu 